\title{
An outline of avalanches in the Tien Shan mountains
}

\author{
Hu Ruji, Ma Hong and Wang Guo \\ Xinjiang Institute of Geography, Academia Sinica, Ürümqi 830011, China
}

\begin{abstract}
The seasonal snow cover in the Tien Shan mountains is characterized by low density, low liquid-water content and low temperature. It is known as typical dry snow. Large temperature gradients in the basal layer of the snow cover exist throughout the entire period of snow accumulation, and depth hoar is therefore extremely well-developed. Full-depth depth-hoar avalanches, however, seldom occur. Avalanches in the Tien Shan mountains are mostly loose snow avalanches. Although normally not large in size, they are the most dangerous type. The occurrence of hazardous avalanches shows cycles of about ten years because of periodic climatic variations.
\end{abstract}

\section{INTRODUCTION}

The Tien Shan mountains lie in central Asia. With a total length of $2500 \mathrm{~km}$ from east to west and between 250 and $400 \mathrm{~km}$ wide $\left(40-45^{\circ} \mathrm{N}, 67-95^{\circ} \mathrm{E}\right)$, the mountain ranges cover an area of about $600000 \mathrm{~km}^{2}$ (Fig. 1). The SinoSoviet border divides the Tien Shan mountains into two parts: the east part in China and west part in the Soviet Union. The highest summit, Tuomuer Peak $(7443.8 \mathrm{~m}$ a.s.l.), is situated in Wenxu County, Xinjiang, China.

Seasonal snow covers are widely distributed, and snowmelt runoff plays an important role in the development of agriculture and other economic activities in this area. Avalanches are an important factor affecting the ecological environment and, from the viewpoint of economical constructions, they are a disadvantageous element.

In fact, reliable records of avalanches in the Tien Shan mountains were kept in China and the Soviet Union 1200 years ago (Borinskiy, 1987; $\mathrm{Hu}, 1989$ ). At the end of the 1950s, the Chinese Road Division, supported by Soviet specialists, began to study and control avalanches at Guozigou along the Ürumqi-Yining Road. During the 1960s, units of Academia Sinica from China and the Soviet Union, together with the local departments, established snow and avalanche stations, and made a breakthrough in avalanche studies. At the end of the 1980s, cooperation between scientists from China and the

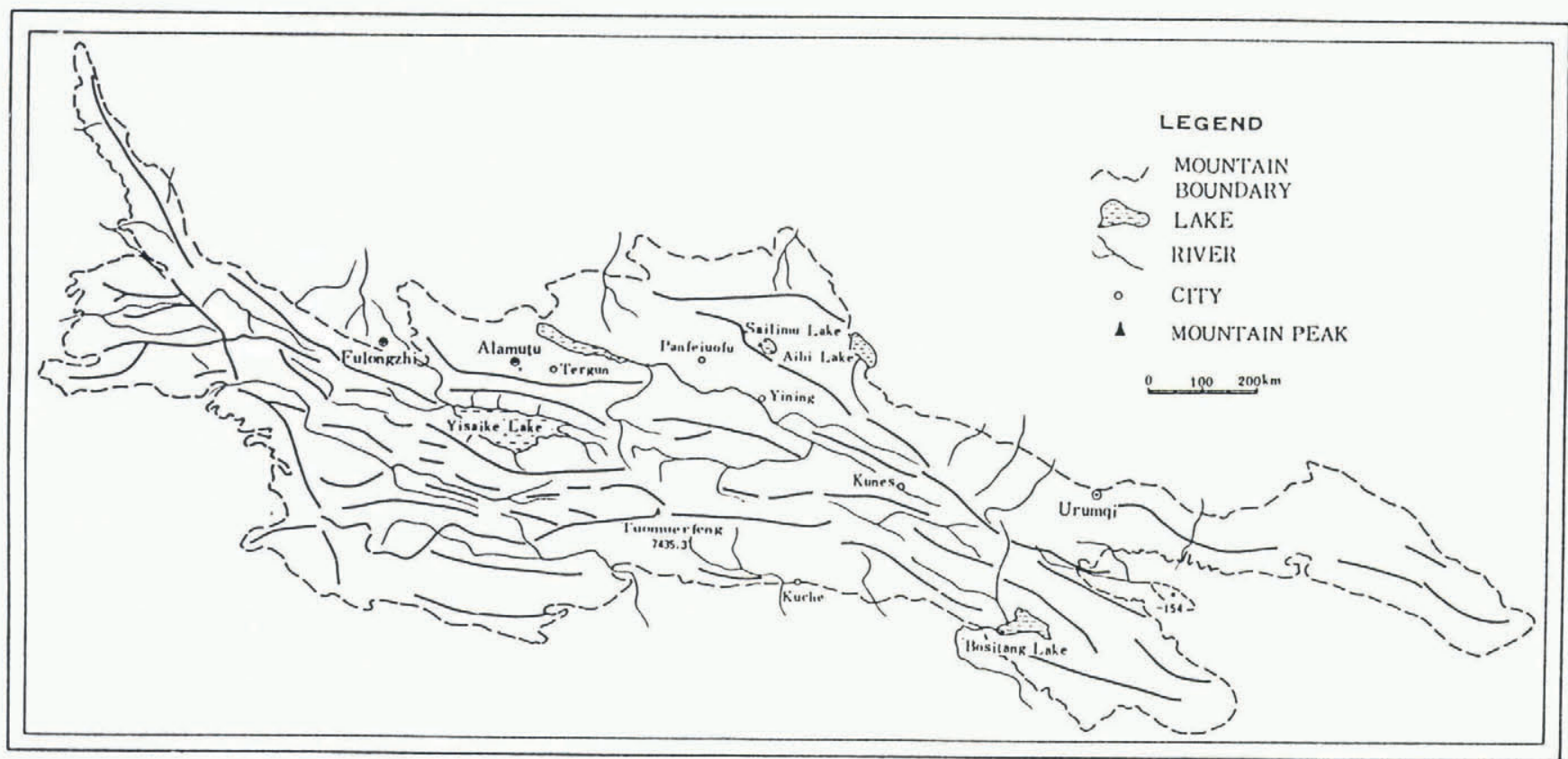

Fig. 1. Map of the Tien Shan mountains. 


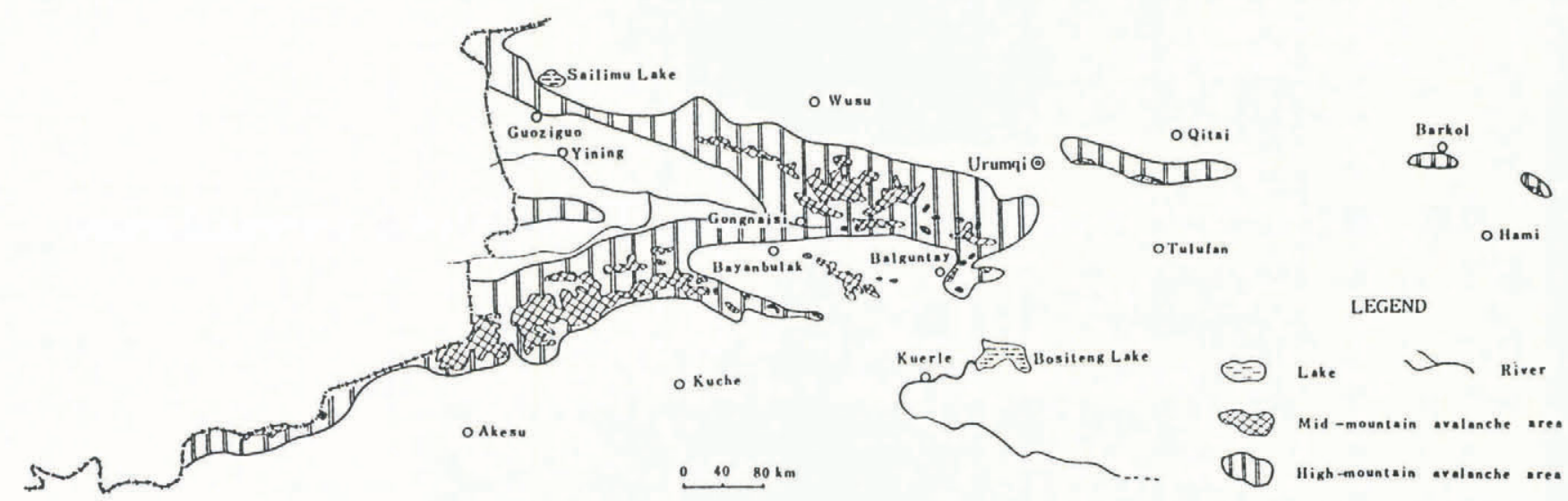

Fig. 2. Distribution of avalanche areas in the Chinese part of the Tien Shan mountains.

Soviet Union advanced avalanche studies in the Tien Shan mountains to a new stage.

\section{AVALANCHES IN THE TIEN SHAN MOUNTAINS}

\section{Basic features of avalanche areas}

Influenced by altitude and westerly winds, avalanche areas in the Tien Shan mountains can be divided into two zones, i.e. high- and mid-mountain avalanche zones (Fig. 2). Avalanche areas in the high mountains have obvious starting zones, tracks, and runout zones with wider extent and longer runout distances than those of the midmountain altitudes. The recorded lower limit of the avalanche paths is about $3000 \mathrm{~m}$ in altitude, and the vertical drop is about $2000 \mathrm{~m}$ (Severskiy and Blagoveshenskiy, 1990).

The avalanche areas in the middle zone of the Tien Shan mountains can be classified into channelled, openslope and mixed types. The channelled avalanche areas have obvious starting zones, tracks and runout zones. Open-slope avalanche areas can be recognized from the terrain features, but the starting zones and tracks are not obvious. Avalanche areas of the mixed type can also be identified from the terrain features, but the starting zones, tracks and runout zones cannot be recognized.

Channelled avalanche areas are widely distributed in the middle zone, accounting for more than $85 \%$ of the total avalanche areas. Full-depth avalanches with runout distances from several tens of metres to $1000 \mathrm{~m}$ are commonly observed.

In the case of the entire mountain range, the distribution of avalanche areas shows vertical zonality and dependence on orientation. The extent and number of avalanche areas increases with increasing altitude. In general, there are more avalanche areas on the northern slopes than on the southern slopes.

\section{Snow conditions in the avalanche areas}

Snow cover in the Tien Shan mountains accumulates mainly through periods of snowfall which occur about ten times during the snow season. The amount of each snowfall is normally no more than $10 \mathrm{~mm}$ of water equivalent (Fig. 3). This situation is almost the same in the western part of the Tien Shan mountains (according to records from Almatinki River basin, USSR). There is usually less snowfall in mid-winter than earlier in the winter. The average precipitation in January varies from $23 \mathrm{~mm}$ in the east to $28 \mathrm{~mm}$ in the western part of the mountains. The amount of snow in the avalanche areas is generally greater than in other areas of the same altitude in these mountains. That is, the amount of snow accumulation in the north-northwest slopes is usually 30 to $50 \%$ less than in the south-southeastern slopes, due to uneven distribution of precipitation.

The mean annual air temperature during the winter season, recorded at the Tien Shan Snow and Avalanche Research Station $\left(43^{\circ} 16^{\prime} \mathrm{N}, 84^{\circ} 24^{\prime} \mathrm{E}\right.$; $1776 \mathrm{~m}$ a.s.l. $)$ is from -7.4 to $-14.0^{\circ} \mathrm{C}$ (November to April 1967-1989), with the lowest at $-36.1^{\circ} \mathrm{C}$. Low air temperatures create

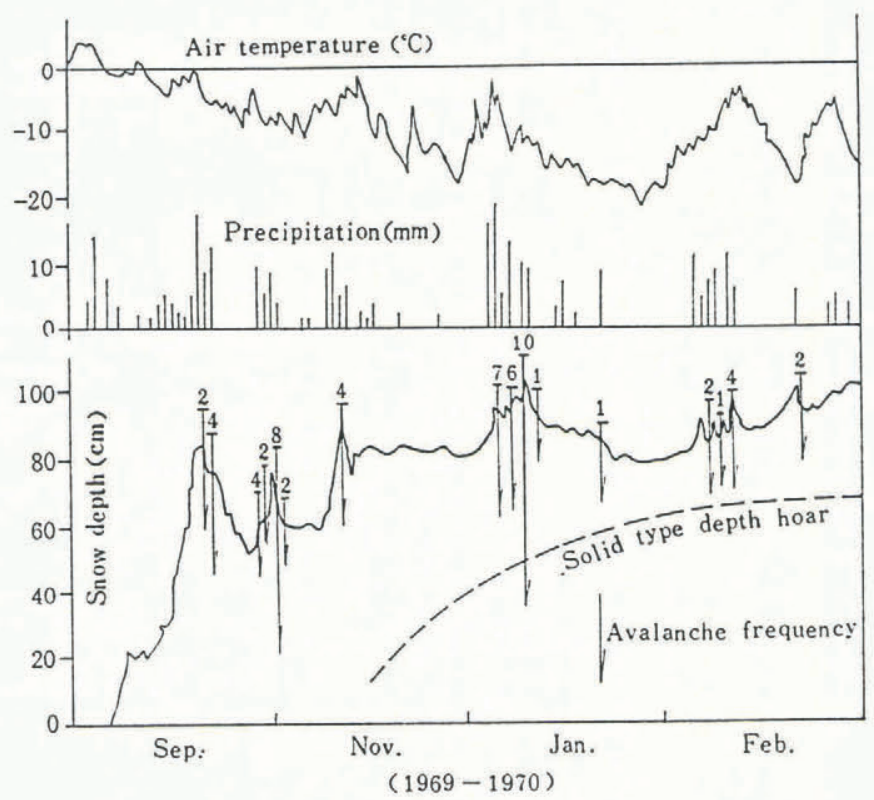

Fig. 3. Diumal precipitation, mean air temperature and snow depth at Tien Shan Snow and Avalanche Research Station $\left(43^{\circ} 16^{\prime} \mathcal{N}, 84^{\circ} 24^{\prime} \mathrm{E}\right.$; $1776 \mathrm{~m}$ a.s.l.). 
(A)Western Tianshan

(Tuerqen, CCCP. Jan. 1988)

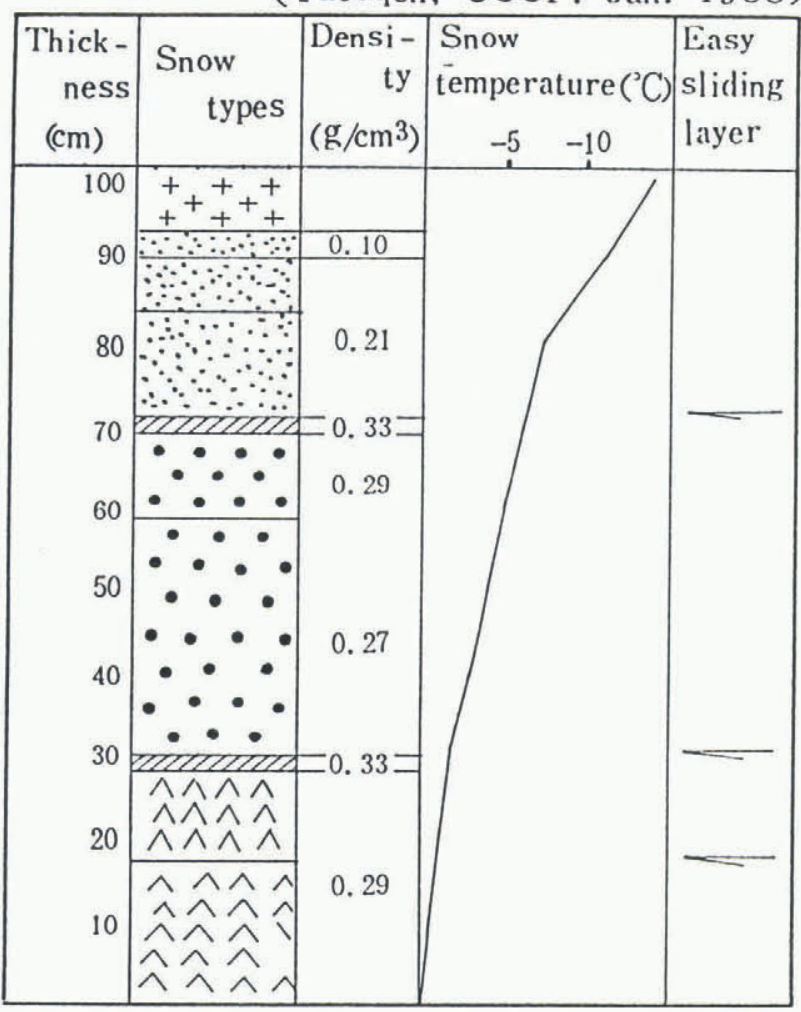

\begin{tabular}{r|r}
++ \\
++
\end{tabular}

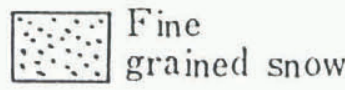

$\triangle \Delta$ Solid type depth hoa.r
(B) Eastern Tianshan

(Gongnisi, PRC. Feb. 1988)

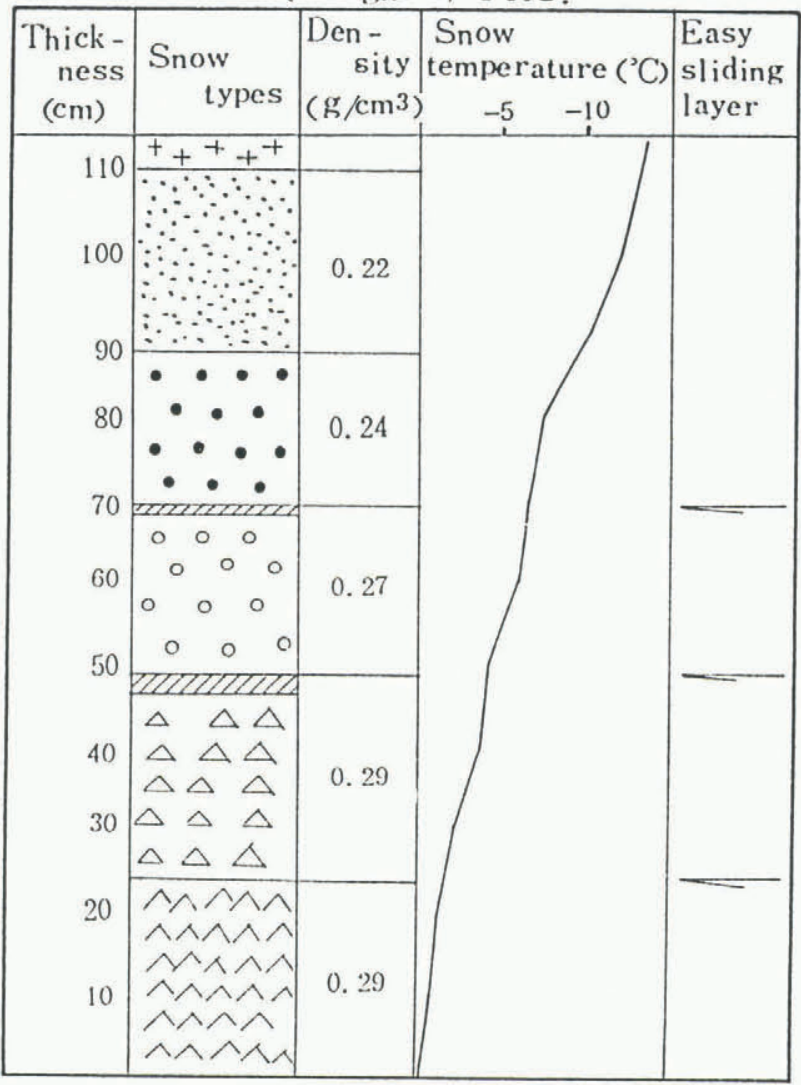

$\begin{array}{ll}\because \because & \text { Medium } \\ \text { grained snow }\end{array}$

oo Coarse grained ○ 0 snow

Melting and refreezing grained snow

Fig. 4. Stratigraphic section of snow covers in eastern and western Tien Shan mountains.

large temperature gradients in the snow cover. The maximum temperature gradient recorded at Gongnisi (in the eastern part of the Tien Shan mountains, 13 January 1972) was $-0.52^{\circ} \mathrm{C} \mathrm{cm}^{-1}$. Because of this, strong vapour migration leads to the formation of well-developed depth hoar in the snow cover during the period of snow accumulation. This is an important characteristic of dry snow cover in these mountains (Fig. 4).

The combined effects of snow conditions, metamorphism, and external factors determine the release of avalanches. According to observations, the mean grainsize of snow in the upper layers of the avalanche areas varies from 3 to $7 \mathrm{~mm}$, snow density is generally from 0.04 to $0.12 \mathrm{~g} \mathrm{~cm}^{-3}$, and from 0.1 to $0.4 \mathrm{~g} \mathrm{~cm}^{-3}$ for metamorphosed snow. The critical minimum depth of snow cover for high winter avalanche release is about 25 to $30 \mathrm{~cm}$. Large avalanches are usually observed when the depth of snow exceeds $70 \mathrm{~cm}$.

\section{Avalanches}

Avalanches in the Tien Shan mountains are mostly of the loose-snow type. Although, in general, not large, they are the most dangerous type in this area. The length of their path is commonly about $200 \mathrm{~m}$, and at maximum up to $500 \mathrm{~m}$. They are mostly released during or shortly after heavy snowfalls. This is the basic characteristic of avalanches in early winters in the Tien Shan mountains. The occurrence of hazardous avalanches shows cycles of about 10 years because of periodic climatic variations (Hu and Jian, 1989).

On clear days, strong solar radiation often causes snow subsurface melting in spite of the negative air temperatures. When snow on the steep slopes is warmed by solar radiation and by heat absorbed by tree trunks, rocks and others objects, the increase of free water in some areas of the snow cover may lead to partial instability of snow, and hence the release of avalanches.

Slab avalanches begin with the fracturing of the snow slab and mostly occur at the end of winter when snow becomes wet (Hu and Jiang, 1989). The fracture lines are generally tens of metres long, and lines longer than several hundred metres are not common. In most cases (over $80 \%$ ), the released slabs do not reach down to the ground but are limited to the upper layers of the snow 
cover. Full-depth depth-hoar avalanches seldom occur in mid-winter in spite of depth hoar being well-developed.

Snow deposited in the runout zone is about two or three times denser than that of snow in the starting zone, and much harder, its density varying with avalanche velocity and the terrain conditions. Runout zones in the Tien Shan mountains are generally on slopes less than $30^{\circ}$. Usually they reach the valley floor, but may, in some cases, extend across the level terrain and up the opposite slopes.

\section{REFERENCES}

Borinskiy, A. N. 1987. General avalanche science. Leningrad,
Hydrology and Meteorology Press.

Hu Ruji. 1989. Protection of mountain roads from snow hazard. Beijing, Press of Science and Technology.

$\mathrm{Hu}$ Ruji and Jiang Fengqing. 1989. Control of avalanche hazard in the Tien Shan mountains, China. Beijing, People's Communication Press.

Severskiy, I. V. and V. P. Blagoveshenskiy. 1990. The area of avalanche hazard in Kazakhstan. Alma-Ata, Kazakhstan Science Press.

The accuracy of references in the text and in this list is the responsibility of the author/s, to whom queries should be addressed. 